WellBeing International

WBI Studies Repository

$1-2010$

\title{
Identification of Parelaphostrongylus odocoilei (Nematoda: Protostrongylidae) First-Stage Larvae in the Feces of Gray Wolves (Canis lupus) by Molecular Methods
}

\author{
Heather M. Bryan \\ University of Saskatchewan \\ Kathrin A. Sim \\ University of Saskatchewan \\ Chris T. Darimont \\ University of California, Santa Cruz \\ Paul C. Paquet \\ University of Calgary \\ Brent Wagner \\ University of Saskatchewan
}

See next page for additional authors

Follow this and additional works at: https://www.wellbeingintlstudiesrepository.org/parasi

Part of the Animal Studies Commons, Other Animal Sciences Commons, and the Veterinary Preventive Medicine, Epidemiology, and Public Health Commons

\section{Recommended Citation}

Bryan, H. M., Sim, K. A., Darimont, C. T., Paquet, P. C., Wagner, B., Muñoz-Fuentes, V., ... \& Chilton, N. B. (2010). Identification of Parelaphostrongylus odocoilei (Nematoda: Protostrongylidae) first-stage larvae in the feces of gray wolves (Canis lupus) by molecular methods. Journal of wildlife diseases, 46(1), 297-302.

This material is brought to you for free and open access by WellBeing International. It has been accepted for inclusion by an authorized administrator of the WBI Studies Repository. For more information, please contact wbisr-info@wellbeingintl.org.

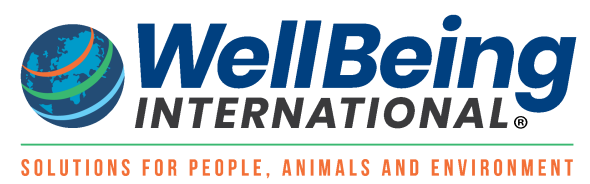


Authors

Heather M. Bryan, Kathrin A. Sim, Chris T. Darimont, Paul C. Paquet, Brent Wagner, Violeta Muñoz-Fuentes, Judit E. Smits, and Nell B. Chilton 


\title{
Identification of Parelaphostrongylus odocoilei (Nematoda: Protostrongylidae) First-Stage Larvae in the Feces of Gray Wolves (Canis lupus) by Molecular Methods
}

\begin{abstract}
Heather M. Bryan, ${ }^{1,2}$ Kathrin A. Sim, ${ }^{3}$ Chris T. Darimont, ${ }^{2,4}$ Paul C. Paquet, ${ }^{2,5}$ Brent Wagner, ${ }^{6}$ Violeta MuñozFuentes, ${ }^{7}$ Judit E. Smits, ${ }^{1}$ and Neil B. Chilton ${ }^{3,8}{ }^{1}$ Department of Veterinary Pathology, Western College of Veterinary Medicine, University of Saskatchewan, 52 Campus Dr., Saskatoon, Saskatchewan S7N 5B4, Canada; 2 Raincoast Conservation Foundation, Box 86, Denny Island, British Columbia V0T 1B0, Canada; ${ }^{3}$ Department of Biology, University of Saskatchewan, 112 Science Place, Saskatoon, Saskatchewan S7N 5E2, Canada; ${ }^{4}$ Environmental Studies Department, 405 ISB, University of California, 1156 High St., Santa Cruz, California 95064, USA; ${ }^{5}$ Faculty of Environmental Design, University of Calgary, 2500 University Dr. NW, Calgary, Alberta T2N 1N4, Canada; ${ }^{6}$ Department of Veterinary Microbiology, Western College of Veterinary Medicine, University of Saskatchewan, 52 Campus Dr., Saskatoon, Saskatchewan S7N 5B4, Canada; ${ }^{7}$ Department of Evolutionary Biology, Uppsala University, Norbyvägen 18D, SE-752 36, Uppsala, Sweden; ${ }^{8}$ Corresponding author (email: neil.chilton@usask.ca)
\end{abstract}

ABSTRACT: First-stage nematode larvae with a dorsal-spine (DSL) were detected in five of 1,565 fecal samples from gray wolves (Canis lupus) collected in British Columbia, Canada, between 2005 and 2008. Molecular techniques were used to identify the DSL because it was not possible to determine their species identity using morphologic characters. The DSL were identified as Parelaphostrongylus odocoilei based on the results of single-strand conformation polymorphism (SSCP) analyses and DNA sequencing of the ribosomal DNA first and second internal transcribed spacers. Finding DSL of $P$. odocoile $i$ in the feces of gray wolves was unexpected because $P$. odocoilei adults are parasites of cervids and bovids. The most likely explanation for the presence of DSL in wolf feces is that they were ingested along with the viscera of recently consumed prey. This was probably black-tailed deer (Odocoileus hemionus columbianus), which are known in the sampling area to be hosts of $P$. odocoilei. The present study demonstrates the use of SSCP and DNA sequencing for the identification, to the species level, of parasitic nematode larvae in feces.

Key words: Accidental parasite, Canis lupus, dorsal-spined nematode larvae, gray wolf, Parelaphostrongylus odocoilei, PCRbased methods, single-strand conformation polymorphism (SSCP).

Identifying the eggs or immature stages (e.g., larvae) of parasite species found in fecal samples based only on their morphologic features is often difficult or impossible (Bowman et al., 2003). Molecular techniques have been used effectively to identify endoparasites in feces, especially species of medical or veterinary significance (Gasser, 2006; Bott et al., 2009). For example, in North America, adult nematodes of five genera within the family Protostrongylidae (Elaphostrongylus, Muellerius, Parelaphostrongylus, Umingmakstrongylus, and Varestrongylus) produce first-stage larvae with a dorsal-spine on the tail (DSL; Anderson, 2000), which cannot be distinguished from one another using morphologic characters (Lankester, 2001). Thus, polymerase chain reaction (PCR), single strand conformation polymorphism (SSCP) analyses, and DNA sequencing have been used to determine the species identity of DSL based on sequence differences in the first or second internal transcribed spacers (ITS-1 and ITS-2, respectively) of nuclear ribosomal (r) DNA (Gajadhar et al., 2000; Chilton et al., 2005; Jenkins et al., 2005; Huby-Chilton et al., 2006a, b; Mortenson et al., 2006; Kutz et al., 2007; Asmundsson et al., 2008).

Recently, during a study of the parasites of gray wolves (Canis lupus) and domestic dogs (C. lupus familiaris) in central and northern coastal British Columbia, Canada, DSL were found in fecal samples from gray wolves. The discovery of DSL in wolf feces was unexpected because adult nematodes that produce DSL are known 
TABLE 1. The number of first-stage nematode larvae with a dorsal-spine (DSL) found in one gram of moist feces from five gray wolves. A total of 1,565 gray wolf fecal samples were collected between 2005 and 2008 from British Columbia, Canada, and examined for DSL.

\begin{tabular}{cllc}
\hline Fecal sample No. & \multicolumn{1}{c}{ Collection dates } & Locality (coordinates) & No. DSL \\
\hline $1,2,3$ & 12 September 2005 & Porcher Island $\left(53^{\circ} 51^{\prime} \mathrm{N}, 130^{\circ} 26^{\prime} \mathrm{W}\right)$ & $383,58,3$ \\
4 & 18 May 2007 & Don Peninsula $\left(52^{\circ} 23^{\prime} \mathrm{N}, 128^{\circ} 11^{\prime} \mathrm{W}\right)$ & 5 \\
5 & 4 August 2007 & Prince Rupert $\left(54^{\circ} 16^{\prime} \mathrm{N}, 130^{\circ} 18^{\prime} \mathrm{W}\right)$ & 3 \\
\hline
\end{tabular}

only in bovids and cervids (Anderson, 2000; Lankester, 2001). The DSL in wolf feces from British Columbia would most likely be Parelaphostrongylus odocoilei or P. andersoni, because these two nematode species commonly occur in ungulates in western Canada (Lankester, 2001; Jenkins et al., 2005). However, there are several other possibilities, including a recently discovered, yet unnamed, species of protostrongylid nematode from ungulates at northern latitudes (Kutz et al., 2007). The aim of the present study was to use molecular tools to determine the species identity of the DSL in the feces of gray wolves.

Fecal samples $(n=1,565)$ from gray wolves were collected between 2005 and 2008 in a remote and sparsely populated area spanning from the northern tip of Vancouver Island $\left(51^{\circ} 46^{\prime} \mathrm{N}, 127^{\circ} 53^{\prime} \mathrm{W}\right)$ to Prince Rupert, British Columbia $\left(55^{\circ} 37^{\prime} \mathrm{N}, 129^{\circ} 48^{\prime} \mathrm{W}\right)$. Samples were stored at $-20 \mathrm{C}$ within $8 \mathrm{hr}$ of collection. Larvae with a dorsal-spine were recovered from thawed fecal samples using a standard sugar flotation technique (Foreyt, 1989) and transferred to microscope slides for morphologic examination using light microscopy (at 100× magnification). Larvae with a dorsal-spine were detected in five $(0.3 \%)$ of the 1,565 fecal samples, and the number of DSL per gram of moist feces ranged from 3 to 383 (Table 1).

Fifteen DSL from a single wolf fecal sample (No. 1; Table 1) were used for the molecular analyses. The source of this fecal sample was analyzed using the molecular methods of Muñoz-Fuentes et al. (2009) and confirmed to be C. lupus based on the sequence comparisons of the mtDNA control region (deposited in GenBank as accession No. FN394215). The DSL were individually placed into a 0.6-ml tube to which $15 \mu \mathrm{l}$ of extraction buffer $(50 \mu \mathrm{l}$ PCR $10 \times$ buffer, $100 \mu \mathrm{l}$ $\mathrm{MgCl}_{2}$, and $350 \mu \mathrm{l}$ DNAse-free $\mathrm{H}_{2} \mathrm{O}$ ) was added. Samples were placed at $90 \mathrm{C}$ for $15 \mathrm{~min}$, and $5 \mu \mathrm{l}$ of Proteinase K (500 $\mu \mathrm{g} /$ $\mathrm{ml}$ ) was added to each tube. Samples were vortexed and placed at $58 \mathrm{C}$ for 12-24 hr. Samples were heated at $90 \mathrm{C}$ for $15 \mathrm{~min}$, and centrifuged at $10,000 \times \mathrm{G}$ for $5 \mathrm{~min}$. The unpurified genomic (g) DNA was used as the template in PCRs. An approximately 180 base-pair (bp) fragment of the ITS-1 rDNA was amplified by PCR from individual DSL using primers F1 (5'GCTCATTATACAAGGTGTCT-3') and R1 (5'-GCATTCTAGCAATGCTCATT$3^{\prime}$; Chilton et al., 2005). This target region (147 bp, excluding the primer binding sites) was used initially because the sequence of $P$. odocoilei differs at one nucleotide position from those of $P$. andersoni and P. tenuis (GenBank accession Nos. FM991897-FM991899; HubyChilton et al., 2006a). Such a sequence difference can be displayed using PCRSSCP (Gasser and Chilton, 2001). Polymerase chain reactions were conducted in $25-\mu \mathrm{l}$ volumes containing $2.5 \mathrm{mM} \mathrm{MgCl} 2$, $62.5 \mu \mathrm{M}$ of each dNTP, $20 \mathrm{pmol}$ of each primer, $0.6 \mathrm{U}$ Taq polymerase, and $5 \mu \mathrm{l}$ of unpurified gDNA. Both negative (no DNA) controls and positive controls (gDNA of $P$. andersoni) were included in each set of PCRs. The PCR conditions used were the same as those used by Chilton et al. (2005). Amplicons were 
subjected to electrophoresis on $1.5 \%$ agarose-TBE (65 mM Tris-HCl, 22.5 $\mathrm{mM}$ boric acid, $1.25 \mathrm{mM}$ EDTA, $\mathrm{pH} 9$ ) gels stained with SYBRsafe (Invitrogen, Carlsbad, California, USA), and visualized with ultraviolet transillumination. The SSCP analysis was performed on these ITS-1 amplicons using precast GMA $^{\mathrm{TM}}$ Wide Mini S-50 gels (Elchrom Scientific, Cham, Switzerland) and the methods described by Huby-Chilton et al. (2006a).

A single band (approximately $180 \mathrm{bp}$ ) was detected on agarose gels for the amplicons derived from the positive controls and 15 DSL from the wolf fecal sample, whereas no bands were detected in the negative control samples (data not shown). The SSCP banding patterns (profiles) of the amplicons from all DSL from the wolf fecal sample on the GMA gels were identical, but they differed from those of the positive controls ( $P$. andersoni; Fig. 1). The amplicons of four DSL from the wolf fecal sample were columnpurified using a MinElute PCR purification kit (Qiagen, Valencia, California, USA) and subjected to automated DNA sequencing using primers $\mathrm{F} 1$ and $\mathrm{R} 1$ in separate reactions. The sequences obtained for the four DSL (147 bp) were identical to one another (deposited in GenBank as accession no. FN377565), and to that for $P$. odocoilei (accession no. FM991898). To further confirm the species identity of the DSL, a larger fragment of the ITS-1 rDNA including the $5^{\prime}$ flanking region ( $76 \mathrm{bp}$ of the $18 \mathrm{~S}$ rRNA gene) was amplified for DSL using primers NC16 (5'-AGTTCAATCGCAATGGCTT-3') and R1, and the PCR conditions of Huby-Chilton et al. (2006a). The DNA sequences of the partial ITS-1 rDNA (316 bp) of three DSL were identical (deposited in GenBank as accession no. FN377566) to that for P. odocoilei (accession no. FM991898). The identity of the DSL as $P$. odocoilei was further supported by the amplification and sequencing of a partial fragment $(230 \mathrm{bp})$ of the ITS-2 rDNA. The sequence obtained

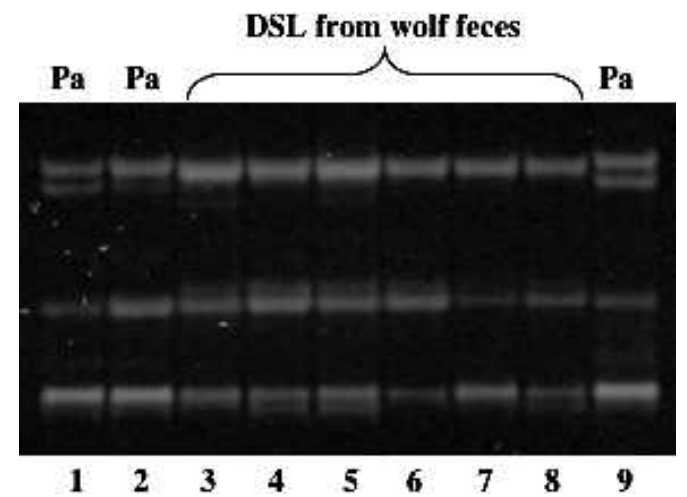

FIgURE 1. Representative gel showing the singlestrand conformation polymorphism profiles of a partial fragment (approximately 180 base-pairs) of the ITS-1 rDNA for amplicons of six dorsal-spined nematode larvae from a gray wolf fecal sample (lanes 3-8) and Parelaphostrongylus andersoni ( $\mathrm{Pa}$; lanes 1, 2 , and 9).

(deposited in GenBank as accession no. FN377567) most closely matched (99.6\%; identical except at a single nucleotide position) the sequence for $P$. odocoilei (accession no. AY648406; Jenkins et al., 2005), as opposed to those of the other protostrongylid species that produce DSL. The species identity of the DSL from the other four wolf fecal samples remains uncertain.

To our knowledge, this is the first report of $P$. odocoilei first-stage larvae in wolf feces. The central and north coasts of British Columbia fall within the distributional range for this parasite (Jenkins et al., 2005). However, the reported definitive hosts of $P$. odocoilei are mule deer (Odocoileus hemionus hemionus), blacktailed deer (O.h. columbianus), caribou (Rangifer tarrandus), mountain goats (Oreamnos americanus), and thinhorn sheep (Ovis dalli; Anderson, 2000; Lankester, 2001; Jenkins et al., 2005). In these hosts, adult $P$. odocoilei are found in association with small veins and lymphatic vessels within muscles (Anderson, 2000). Nematode eggs are passed from the circulatory system to the lungs where they hatch as first-stage larvae. These larvae are passed up the respiratory tract into the digestive 
tract and out in the feces (Anderson, 2000; Lankester, 2001). The first-stage larvae then require an intermediate host (terrestrial gastropods such as Deroceras laeve) to complete their development to thirdstage larvae (Anderson, 2000). The definitive hosts become infected with $P$. odocoilei following consumption of gastropods containing infective third-stage larvae (Anderson, 2000; Lankester, 2001). It is unlikely that wolves represent a definitive host for this parasite because $P$. odocoilei adults have not been reported in any of the 27 published reports on necropsies conducted on hundreds of wolves (Craig and Craig, 2005), and as carnivores, wolves rarely consume vegetation on which infective gastropods containing $P$. odocoilei third-stage larvae are found (Milne et al., 1989; Paquet and Carbyn, 2003; Peterson and Ciucci, 2003).

The most plausible explanation for the presence of $P$. odocoilei first-stage larvae in wolf feces is that the wolves have obtained the parasites by ingesting viscera or feces of an ungulate host infected with P. odocoilei. Black-tailed deer make up a large proportion $(>80 \%)$ of the diet of wolves in the study area (Darimont et al., 2008) and are, therefore, the most likely source of DSL in wolf feces. Wolves are also known to preferentially feed on the fatty omentum and internal organs of their prey, including the lungs and intestines (Mech, 1970; Stahler et al., 2006; Paquet, pers. obs.) where DSL would be present. Parelaphostrongylus odocoilei DSL would then pass through the wolf digestive tract and be deposited in wolf feces. Several studies have reported the presence of other parasites within the feces of wolves that are normally only found in their prey species (Byman et al., 1977; MarquardPetersen, 1997; Duszynski and Upton, 2001; Sallows, 2007). Marquard-Petersen (1997) reported the presence of an egg of a trichostrongylid nematode (Nematodirus spp.) in one of 423 wolf fecal samples from Greenland. Given the low $(<1 \%)$ frequency of this parasitic nematode, its presence in wolf feces was attributed to the consumption of an infected muskox (Ovibos moschatus) by a wolf (MarquardPetersen, 1997). Similarly, DSL were detected in only $<1 \%$ of fecal samples analyzed in the present study, which also suggests that $P$. odocoilei is not a parasite of wolves.

In conclusion, molecular techniques can be used to identify unknown parasitic nematode larvae recovered from the feces of gray wolves. Such an approach, when combined with the molecular typing of feces to confirm host identity, enhances the utility of coprologic studies to provide information on the diversity, prevalence, and relative abundance of endoparasites in gray wolves. This is particularly important for wolf populations in central and northern British Columbia, where it is neither ethical nor permitted to trap and kill individuals for postmortem examination.

We thank the Heiltsuk, Kitasoo-Xai'xais, Wuikinuxv, and Gitga'at Nations for allowing us to collect samples within their traditional territories. We also thank A. Adams, D. Brown, R. Bryan, N. DeBruyn, R. Eustace, M. Gouix, J. Leonard, H. Recker, and D. and S. Watson for their assistance in sample collection or conducting the fecal flotations. Funding for the collection of samples was provided by the Raincoast Conservation Foundation, the Wilburforce Foundation, the Summerlee Foundation, the Paquet Family Foundation, the World Wildlife Fund-Canada and the Vancouver Foundation. The nematode molecular work was funded by a Natural Sciences and Engineering Research Council of Canada (NSERC) Discovery Grant RGPIN298374-04 to NBC. NSERC also provided a Graduate Scholarship to $\mathrm{HMB}$, an Undergraduate Student Research Award to KAS, and a Postdoctoral Fellowship to CTD. The European Union Marie Curie Fellowship programme and the Spanish Ministry of Education provided funding to VMF. The University of Saskatchewan Animal Care Committee approved this research. We also thank 
M. Lankester for his valuable comments on the manuscript.

\section{LITERATURE CITED}

Anderson, R. C. 2000. Chapter 3. Order Strongylida (The bursate nematodes). In Nematode parasites of vertebrates. Their development and transmission, R. C. Anderson (ed.). C.A.B.I. Publishing, Wallingford, UK, pp. 41-229.

Asmundsson, I. M., J. A. Mortenson, And E. P. Hoberg. 2008. Muscleworms, Parelaphostrongylus andersoni (Nematoda: Protostrongylidae), discovered in Columbia white-tailed deer from Oregon and Washington: Implications for biogeography and host associations. Journal of Wildlife Diseases 44: 16-27.

Bott, N. J., B. E. Campbell, I. Beveridge, N. B. Chilton, D. Rees, P. R. Hunt, and R. B. Gasser. 2009. A combined microscopic-molecular method for the diagnosis of strongylid infections in sheep. International Journal for Parasitology 39: 1277-1287.

Bowman, D. D., R. C. Lynn, and D. M. L. Eberhard. 2003. Georgis' parasitology for veterinarians. Elsevier Science, Saint Louis, Missouri, 451 pp.

Byman, D., V. Van Ballenberghe, J. C. Schlottauer, and A. W. Erickson. 1977. Parasites of wolves, Canis lupus L., in northeastern Minnesota, as indicated by analysis of fecal samples. Canadian Journal of Zoology 55: 376-380.

Chilton, N. B., F. Huby-Chilton, M. W. Lankester, and A. A. Gajadhar. 2005. A method for extracting genomic DNA from individual elaphostrongyline (Nematoda: Protostrongylidae) larvae and differentiation of Elaphostrongylus spp. from Parelaphostrongylus spp. by PCR assay. Journal of Veterinary Diagnostic Investigation 17: 585-588.

Craig, H. L., and P. S. Craig. 2005. Helminth parasites of wolves (Canis lupus): A species list and an analysis of published prevalence studies in Nearctic and Palaearctic populations. Journal of Helminthology 79: 95-103.

Darimont, C. T., P. C. Paquet, and T. E. Reimchen. 2008. Spawning salmon disrupt trophic coupling between wolves and ungulate prey in coastal British Columbia. BMC Ecology 8: 14.

Duszynski, D. W., and S. J. Upton. 2001. Enteric protozoans. Cyclospora, Eimeria, Isospora, and Cryptosporidium spp. Chapter 16. In Parasitic diseases of wild mammals, W. M. Samuel, M. J. Pybus, and A. A. Kocan (eds.). Iowa State University Press, Ames, Iowa, pp. 416-459.

Foreyt, W. J. 1989. Diagnostic parasitology. Veterinary Clinics of North America-Small Animal Practice 19: 979-1000.

Gajadhar, A., T. Steeves-Gurnsey, J. Kendall, M. Lankester, and M. Steen. 2000. Differentiation of dorsal-spined elaphostrongyline larvae by polymerase chain reaction amplification of ITS2 of rDNA. Journal of Wildlife Diseases 36: 713722.

GAsser, R. B. 2006. Molecular tools-advances, opportunities and prospects. Veterinary Parasitology 136: 69-89.

-, And N. B. Chilton. 2001. Applications of single-strand conformation polymorphism (SSCP) to taxonomy, diagnosis, population genetics and molecular evolution of parasitic nematodes. Veterinary Parasitology 101: 201213.

Huby-Chilton, F., N. B. Chilton, M. W. Lankester, AND A. A. GajadHAR. 2006a. Single-strand conformation polymorphism (SSCP) analysis as a new diagnostic tool to distinguish dorsal-spined larvae of the Elaphostrongylinae (Nematoda: Protostrongylidae) from cervids. Veterinary Parasitology 135: 153-162.

- A. A. Gajadhar, K. Mansfield, W. J. Foreyt, And N. B. Chilton. 2006b. Bighorn sheep, a new host record for Parelaphostrongylus odocoilei (Nematoda: Protostrongylidae). Journal of Wildlife Diseases 42: 877-882.

Jenkins, E. J., G. D. Appleyard, E. P. Hoberg, B. M. Rosenthal, S. J. Kutz, A. M. Veitch, H. M. Schwantje, B. T. Elkin, and L. Polley. 2005. Geographic distribution of the muscle-dwelling nematode Parelaphostrongylus odocoilei in North America, using molecular identification of first-stage larvae. Journal of Parasitology 91: 574-584.

Kutz, S. J., I. Asmundsson, E. P. Hoberg, G. D. Appleyard, E. J. Jenkins, K. Beckmen, M. Branigan, L. Butler, N. B. Chilton, D. Cooley, B. Elkin, F. Huby-Chilton, D. Johnson, A. Kuchboev, J. Nagy, M. OAkley, L. Polley, R. Popko, A. Scheer, M. Simard, and A. Veitch. 2007. Serendipitous discovery of a novel protostrongylid (Nematoda: Metastrongyloidea) in caribou, muskoxen, and moose from high latitudes of North America based on DNA sequence comparisons. Canadian Journal of Zoology 85: 1143-1156.

Lankester, M. W. 2001. Extrapulmonary lungworms of cervids. Chapter 9. In Parasitic diseases of wild mammals, W. M. Samuel, M. J. Pybus, and A. A. Kocan (eds.). Iowa State University Press, Ames, Iowa, pp. 228-278.

Marquard-Petersen, U. 1997. Endoparasites of arctic wolves in Greenland. Arctic 50: 349-354.

Mech, D. L. 1970. The wolf: The ecology and behavior of an endangered species. University of Minnesota Press, Minneapolis, Minnesota, $384 \mathrm{pp}$.

Milne, D. G., A. S. Harestad, and K. Atkinson. 1989. Diets of wolves on Northern Vancouver Island. Northwest Scientist 63: 83-86.

Mortenson, J. A., A. Abrams, B. M. Rosenthal, D. B. Dunams, E. P. Hoberg, R. J. Bildfell, and R. 
L. Green. 2006. Parelaphostrongylus odocoilei in Oregon black-tailed deer. Journal of Wildlife Diseases 42: 527-535.

Muñoz-Fuentes, V., C. T. Darimont, R. K. Wayne, P. C. Paquet, and J. A. Leonard. 2009. Ecological factors drive differentiation in wolves in British Columbia. Journal of Biogeography 31: 1516-1531.

Paquet, P. C., and L. N. Carbyn. 2003. Gray wolves. In Mammals of North America, 2nd Edition, G. Feldhamer and B. Thomspon (eds.). Johns Hopkins University Press, Baltimore, Maryland, pp. $482-510$.

Peterson, R. O., And P. Ciucci. 2003. The wolf as a carnivore. In Wolves: Behaviour, ecology, and conservation, L. D. Mech and L. Boitani (eds.). University of Chicago Press, Chicago, Illinois, pp. 104-130.

SALLOWS, T. A. 2007. Diet preference and parasites of grey wolves in Riding Mountain National Park of Canada. MEnv Dissertation, University of Manitoba, Winnipeg, Manitoba, Canada, 90 pp.

Stahler, D. R., D. W. Smith, and D. S. Guernsey. 2006. Foraging and feeding ecology of the gray wolf (Canis lupus): Lessons from Yellowstone National Park, Wyoming, USA. Journal of Nutrition 136: 1923S-1926S.

Received for publication 9 August 2009 